\title{
Novel lactoferrin-conjugated amphiphilic poly(aminoethyl ethylene phosphate)/ poly(L-lactide) copolymer nanobubbles for tumor-targeting ultrasonic imaging
}

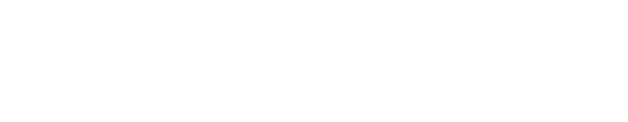

\author{
Binhua Luo ${ }^{1,2, *}$ \\ Huageng Liang,* \\ Shengwei Zhang ${ }^{3}$ \\ Xiaojuan Qin ${ }^{4}$ \\ Xuhan Liu' \\ Wei Liu ${ }^{1,5}$ \\ Fuqing Zeng ${ }^{3}$ \\ Yun $\mathrm{Wu}^{6}$ \\ Xiangliang Yang ${ }^{1,5}$ \\ 'College of Life Science and \\ Technology, Huazhong University \\ of Science and Technology, Wuhan, \\ ${ }^{2}$ College of Pharmacy, Hubei \\ University of Science and Technology, \\ Xianning, ${ }^{3}$ Department of Urology, \\ Union Hospital of Tongji Medical \\ College, Huazhong University \\ of Science and Technology, Wuhan, \\ ${ }^{4}$ Department of Medical Ultrasound, \\ Union Hospital of Tongji Medical \\ College, Huazhong University \\ of Science and Technology, Wuhan, \\ ${ }^{5} \mathrm{National}$ Engineering Research \\ Center for Nanomedicine, Huazhong \\ University of Science and Technology, \\ Wuhan, People's Republic of China; \\ ${ }^{6}$ Department of Biomedical Engineering, \\ University at Buffalo, State University \\ of New York, Buffalo, NY, USA \\ *These authors contributed equally \\ to this work
}

Correspondence: Wei Liu College of Life Science and Technology, Huazhong University of Science and Technology, 1037 Luoyu Road, Wuhan 430074, People's Republic of China Tel +86 2787792147

Fax +86 2787792234

Email wliu@hust.edu.cn

\begin{abstract}
In the study reported here, a novel amphiphilic poly(aminoethyl ethylene phosphate)/ poly(L-lactide) (PAEEP-PLLA) copolymer was synthesized by ring-opening polymerization reaction. The perfluoropentane-filled PAEEP-PLLA nanobubbles (NBs) were prepared using the $\mathrm{O}_{1} / \mathrm{O}_{2} / \mathrm{W}$ double-emulsion and solvent-evaporation method, with the copolymer as the shell and liquid perfluoropentane as the core of NBs. The prepared NBs were further conjugated with lactoferrin (Lf) for tumor-cell targeting. The resulting Lf-conjugated amphiphilic poly(aminoethyl ethylene phosphate)/poly(L-lactide) nanobubbles (Lf-PAEEP-PLLA NBs) were characterized by photon correlation spectroscopy, polyacrylamide gel electrophoresis, Fourier transform infrared spectroscopy, and transmission electron microscopy. The average size of the Lf-PAEEP-PLLA NBs was $328.4 \pm 5.1 \mathrm{~nm}$, with polydispersity index of $0.167 \pm 0.020$, and zeta potential of $-12.6 \pm 0.3 \mathrm{mV}$. Transmission electron microscopy imaging showed that the Lf-PAEEP-PLLA NBs had a near-spherical structure, were quite monodisperse, and there was a clear interface between the copolymer shell and the liquid core inside the NBs. The Lf-PAEEP-PLLA NBs also exhibited good biocompatibility in cytotoxicity and hemolysis studies and good stability during storage. The high cellular uptake of Lf-PAEEP-PLLA NBs in C6 cells (low-density lipoprotein receptor-related protein 1-positive cells) at concentrations of $0-20 \mu \mathrm{g} / \mathrm{mL}$ indicated that the Lf provided effective targeting for brain-tumor cells. The in vitro acoustic behavior of Lf-PAEEP-PLLA NBs was evaluated using a B-mode clinical ultrasound imaging system. In vivo ultrasound imaging was performed on tumor-bearing BALB/c nude mice, and compared with SonoVue ${ }^{\circledR}$ microbubbles, a commercial ultrasonic contrast agent. Both in vitro and in vivo ultrasound imaging indicated that the Lf-PAEEP-PLLA NBs possessed strong, long-lasting, and tumor-enhanced ultrasonic contrast ability. Taken together, these results indicate that Lf-PAEEP-PLLA NBs represent a promising nano-sized ultrasonic contrast agent for tumor-targeting ultrasonic imaging.
\end{abstract}

Keywords: PAEEP-PLLA copolymer, in vitro acoustic behavior, in vivo ultrasonic imaging, SonoVue ${ }^{\circledR}$ microbubbles

\section{Introduction}

Ultrasonography is a widely used, non-invasive diagnostic technique, which can provide real-time imaging in clinical diagnosis. Recently, contrast-enhanced ultrasonic imaging has become an indispensable part of clinical ultrasonography. ${ }^{1,2}$ As effective contrast agents, gas-filled microbubbles have been widely employed in contrastenhanced ultrasound imaging. ${ }^{3}$ Microbubbles are filled with gas and stabilized by lipids, surfactants, polymers, or other proprietary shell materials; therefore, they can 
be injected intravenously to produce echogenic contrast. ${ }^{4}$ In addition, microbubbles can be "explosive" under ultrasonic illumination, which promotes the destruction of bubbles and enhances cellular-membrane permeability change. Consequently, microbubbles are considered ultrasound-mediated drug/gene delivery vehicles to facilitate drug release and extravascular delivery besides diagnostic application. ${ }^{5-7}$ However, the diameters of microbubbles are usually a few microns $(2-8 \mu \mathrm{m})$, which makes microbubbles trapped in the blood pool and poses severe limitations in tumor ultrasonic imaging and drug/gene delivery due to their large sizes. ${ }^{8}$

Recently, nanoscale bubbles (nanobubbles [NBs]) have attracted investigators in extravascular ultrasonic imaging and drug/gene delivery. ${ }^{9-12} \mathrm{NBs}$ of less than $700 \mathrm{~nm}$ can pass through the larger-than-usual pores in the leaky vasculature of tumors. The endothelial cells of the blood vessels in normal tissue, however, have tighter inter-endothelial junctions, which would not allow the penetration of NBs. In contrast, tumor tissue usually retains defective vasculature with large gaps. ${ }^{13}$ As a matter of fact, it appears that the characteristic pore cutoff size ranges from $380 \mathrm{~nm}$ to $780 \mathrm{~nm}$ for a large variety of tumors. ${ }^{14}$ Consequently, NBs can effectively accumulate in the tumor interstitium due to the enhanced permeability and retention effect, which naturally enables them to serve as promising contrast agents for tumor ultrasonic imaging and treatment. ${ }^{11,15,16}$

NBs usually contain a gaseous perfluorocarbon or sulfur hexafluoride as cores, and their shells are composed of albumin, lipids, nonionic surfactants, and polymers. ${ }^{16-19}$ Polymer-based hard-shell NBs are superior to phospholipid/surfactant-based soft-shell NBs because the hard shell makes those NBs more stable and thus have longer circulation life. ${ }^{20,21}$ However, the mechanical properties, degradation time, and hydrophilic/lipophilic feature of the reported copolymers, such as polylactic acid, poly(lacticco-glycolic acid), and polycaprolactone, are difficult to adjust to meet the requirements of clinical ultrasound imaging. These polymers lack active sites for conjugating tumor-targeting molecules. Moreover, previous studies have focused on enhancing the contrast capabilities of the NBs, and their active tumor-targeting potential has not been well explored.

Lactoferrin (Lf) is a single-chain iron-binding glycoprotein belonging to the transferrin (Tf) family. ${ }^{22} \mathrm{Tf}$ is used as a tumor-targeting ligand because Tf receptors are overexpressed in several human carcinomas including brain, breast, and ovary cancers..$^{23,24}$ In our recent work, Lf-conjugated nanoparticles were developed as the specific and multifunctional magnetic resonance imaging contrast agent for the diagnosis of brain glioma. ${ }^{25,26} \mathrm{In}$ the study reported here, a novel amphiphilic biodegradable poly(aminoethyl ethylene phosphate)/poly(L-lactide) (PAEEP-PLLA) copolymer was synthesized by ringopening polymerization reaction. The NBs were prepared with PAEEP-PLLA copolymer as the shell and liquid perfluoropentane (PFP) as the core. Lf was conjugated to the PAEEP-PLLA NBs for tumor targeting. The physiochemical properties (size, size distribution, zeta potential, and morphology), biocompatibility, and Lf targeting effect of the Lf-PAEEP-PLLA NBs were investigated. The ultrasound-triggered phase transition and in vitro and in vivo ultrasonic imaging behavior of the NBs were evaluated using a B-mode clinical ultrasound imaging system.

\section{Materials and methods Materials}

L-lactide was purchased from Daigang Biotechnology Co, Ltd (Shandong, People's Republic of China) and was recrystallized from dry ethyl acetate prior to use. Stannous octoate $\left[\mathrm{Sn}(\mathrm{Oct})_{2}\right]$, Lf from bovine colostrum, and 2-iminothiolane hydrochloride were purchased from Sigma-Aldrich Co (St Louis, MO, USA). Poly(vinyl alcohol) (PVA-217, the degree of polymerization is 1700 , and the degree of hydrolysis is $88.5 \%$ ) was obtained from Kuraray Co, Ltd (Tokyo, Japan). PFP was obtained from Strem Chemicals, Inc (Newburyport, MO, USA), while 2-chloro-2-oxo-1, 3,2-dioxaphospholane (COP) was purchased from Tokyo Chemical Industry Co, Ltd (Tokyo, Japan); $\alpha$-malemidyl- $\omega$ N-hydroxysuccinimidylpoly (ethylene glycol) (MW3400) was obtained from Jenkem Technology Co, Ltd (Beijing, People's Republic of China); and ethanolamine and di-tert-butyl dicarbonate were purchased from Aladdin Industrial Corporation (Shanghai, People's Republic of China). Triethylamine and tetrahydrofuran were purchased from Sinopharm Chemical Reagent Co, Ltd (Shanghai, People's Republic of China) and dried and distilled prior to use.

\section{Synthesis of amino-terminated PLLA $_{130}-\mathrm{OH}$}

$\mathrm{PLLA}_{130}-\mathrm{OH}$ was synthesized with the ring-opening polymerization reaction of L-lactide. EABoc and $\mathrm{Sn}(\mathrm{Oct})_{2}$ were used as the initiator and catalyst, respectively. In a glove box $\left(\mathrm{H}_{2} \mathrm{O}\right.$ and $\mathrm{O}_{2}$ contents less than $\left.0.1 \mathrm{ppm}\right)$, L-lactide $(1.4771 \mathrm{~g}$, $10 \mathrm{mmol})$, EABoc $(0.0161 \mathrm{~g}, 0.1 \mathrm{mmol})$, and $\mathrm{Sn}(\mathrm{Oct})_{2}$ $(0.0045 \mathrm{~g}, 0.01 \mathrm{mmol})$ were added into a freshly flamed 
nitrogen-purged round-bottomed flask. The resulting mixture was maintained at $120^{\circ} \mathrm{C}$ for 3 hours. The crude material was first dissolved in $30 \mathrm{~mL}$ of chloroform. Then the desired product was gradually precipitated, followed by washing with $100 \mathrm{~mL}$ of cold methanol twice. The precipitates were dried under vacuum until a constant weight was obtained. The average degree of polymerization of L-lactide was calculated based on its GPC results. The proton nuclear magnetic resonance $\left({ }^{1} \mathrm{H} \mathrm{NMR}\right)$ spectrum is shown in Figure $1 \mathrm{~A}\left(100 \mathrm{MHz} ; \mathrm{CDCl}_{3} ; \mathrm{Me}_{4} \mathrm{Si} ; \mathrm{ppm}\right)$.

\section{Synthesis of N-(t-butoxycarbonyl) ethanolamine}

Sodium bicarbonate solution $(0.84 \mathrm{~g}, 0.01 \mathrm{~mol}$ in $10 \mathrm{~mL}$ water $)$ was added to the solution of ethanolamine $(0.6 \mathrm{~g}, 0.01 \mathrm{~mol})$ in $10 \mathrm{~mL}$ tetrahydrofuran at $0^{\circ} \mathrm{C}$. Di-tert-butyl dicarbonate

\section{A}

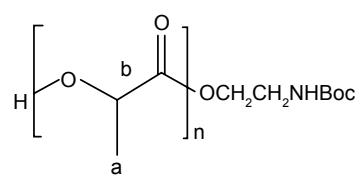

B
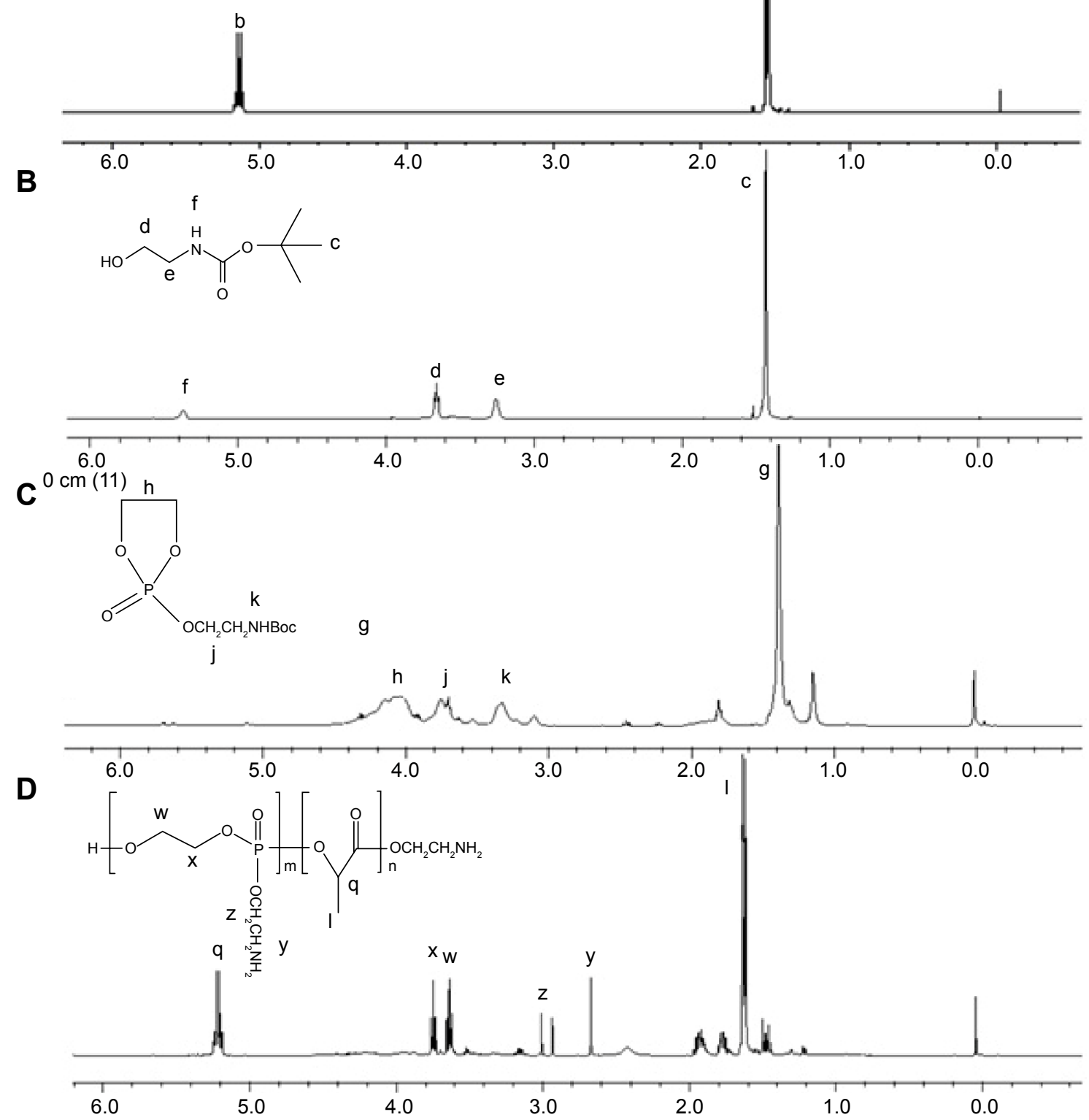

Figure I Proton nuclear magnetic resonance spectra (in $\mathrm{CDC}_{13}$, Ppm) of (A) poly(L-lactide), (B) EABoc, (C) 2-N-(t-butoxycarbonyl) ethanolamine-2-oxo-I,3, 2-dioxaphospholane, and (D) poly(aminoethyl ethylene phosphate)/poly(L-lactide) copolymer. 
(2.18 g, $0.01 \mathrm{~mol})$ was added dropwise over a period of 0.5 hours with magnetic stirring. The resulting mixture was stirred overnight at room temperature and extracted three times with diethyl ether. The organic phase was combined and dried with sodium sulfate. N-(t-butoxycarbonyl) ethanolamine (EABoc) was obtained after vacuum distillation. The ${ }^{1} \mathrm{H}$ NMR spectrum is shown in Figure 1B (100 MHz; $\left.\mathrm{CDCl}_{3} ; \mathrm{Me}_{4} \mathrm{Si} ; \mathrm{ppm}\right)$.

\section{Synthesis of monomer 2-N-(t- butoxycarbonyl) ethanolamine-2-oxo- I,3,2-dioxaphospholane}

At $-10^{\circ} \mathrm{C}$, COP solution $(1.425 \mathrm{~g}, 0.01 \mathrm{~mol}$ in $3 \mathrm{~mL}$ anhydrous tetrahydrofuran) was added dropwise to the solution of EABoc $(1.61 \mathrm{~g}, 0.01 \mathrm{~mol})$ and triethylamine $(1.0120 \mathrm{~g}$, $0.01 \mathrm{~mol}$ ) in $12 \mathrm{~mL}$ anhydrous tetrahydrofuran over a period of 0.5 hours. The mixture was maintained at $-10^{\circ} \mathrm{C}$ overnight under magnetic stirring. Subsequently, the solid precipitates, which should have been triethylammonium chloride, were removed by filtration using a Schlenk funnel. The filtrate was concentrated under vacuum, then re-precipitated from $40 \mathrm{~mL}$ of cold anhydrous diethyl ether. The resulting material was dried under vacuum at $40^{\circ} \mathrm{C}$, affording the final monomer product. The ${ }^{1} \mathrm{H}$ NMR spectrum is shown in Figure 1C (100 MHz; $\left.\mathrm{CDCl}_{3} ; \mathrm{Me}_{4} \mathrm{Si} ; \mathrm{ppm}\right)$.

\section{Synthesis of PAEEP-PLLA block copolymers}

The PAEEP-PLLA block copolymers featuring different PEEA chain lengths were synthesized by the ring-opening polymerization reaction of $\mathrm{N}$-(t-butoxycarbonyl) ethanolamine-2-oxo-1,3,2-dioxaphospholane (PEEABoc). The PLLA $_{130}-\mathrm{OH}$ macro-initiator with $\mathrm{Sn}(\mathrm{Oct})_{2}$ was employed as the catalyst. In a glove box $\left(\mathrm{H}_{2} \mathrm{O}\right.$ and $\mathrm{O}_{2}$ content less than $0.1 \mathrm{ppm}), \mathrm{PLLA}_{130}-\mathrm{OH}(0.47 \mathrm{~g}, 0.025 \mathrm{mmol})$ and PEEABoc $(0.557 \mathrm{~g}, 2.5 \mathrm{mmol})$ were dissolved in $5 \mathrm{~mL}$ of anhydrous tetrahydrofuran, then $\mathrm{Sn}(\mathrm{Oct})_{2}(0.01 \mathrm{~g}, 0.025 \mathrm{mmol})$ was added to the solution. The resulting mixture was stirred at $40^{\circ} \mathrm{C}$ for 2 hours, and the concentrated polymer product was precipitated twice using a mixture of diethyl ether/isopropyl alcohol $(4: 1, \mathrm{v} / \mathrm{v})$ and dried under vacuum until a constant weight was obtained.

\section{De-protection of t-butoxycarbonyl (Boc)}

At $0^{\circ} \mathrm{C}, 4 \mathrm{~mol} / \mathrm{L}$ hydrogen chloride solution in tetrahydrofuran was added to the copolymers under magnetic stirring over 1 hours. The product was collected by centrifugation and dried under vacuum. The reaction yield of the final product was $70.7 \%$. The ${ }^{1} \mathrm{H}$ NMR spectrum is shown in
Figure 1D (100 MHz; $\left.\mathrm{CDCl}_{3} ; \mathrm{Me}_{4} \mathrm{Si} ; \mathrm{ppm}\right)$. A Diamond ${ }^{\mathrm{TM}}$ DSC (differential scanning calorimeter; PerkinElmer Inc, Waltham, MA, USA) was employed to detect the thermodynamic properties of the PAEEP-PLLA copolymer. The lyophilized copolymer was weighed and placed in a sealed aluminum crimp cell then heated from $50^{\circ} \mathrm{C}$ to $200^{\circ} \mathrm{C}$ at a rate of $5^{\circ} \mathrm{C} /$ minute.

\section{Preparation of PAEEP-PLLA NBs}

PAEEP-PLLA NBs were prepared by a double-emulsion (oil-in-oil-in-water, $\mathrm{O}_{1} / \mathrm{O}_{2} / \mathrm{W}$ ) and solvent-evaporation method. PAEEP-PLLA $(50 \mathrm{mg})$ was first dissolved in $2 \mathrm{~mL}$ dichloromethane. PFP $(0.5 \mathrm{~mL})$ was added to the solution then the solution was placed in a high-shear mixer (Fluko FA25 homogenizer; Fluko Equipment Shanghai Co, Ltd, Shanghai, People's Republic of China) for 1 minute at $10,000 \mathrm{rpm}$ in an ice bath while in the dark, ultimately forming a primary emulsion. The primary emulsion was added dropwise into $12 \mathrm{~mL} 0.3 \%$ PVA solution, with magnetic stirring in an ice bath, to produce the coarse double emulsion. The coarse double emulsion was sonicated for 10 seconds at 100 Watts, then stirred in an ice bath overnight. Organic solvents were removed by evaporation, and NBs were formed after solidification. The NB dispersion was centrifuged (10,000 rpm, $10 \mathrm{~min}$ utes) to obtain NB precipitates, which were dispersed in normal saline solution and then stored at $4{ }^{\circ} \mathrm{C}$ for further studies.

\section{Conjugation of Lf to PAEEP-PLLA NBs}

Sulfhydryl groups were linked to Lf molecules using Traut's reagent. A cold solution of $0.0024 \mathrm{~g} \mathrm{Lf}$ in $1 \mathrm{~mL}$ of $0.1 \mathrm{M}$ sodium phosphate buffer $(\mathrm{pH} 8.0$, containing $5 \mathrm{mM}$ EDTA) was mixed with $1.0 \mathrm{~mL}$ of 2-iminothiolane solution $(0.24 \mathrm{mg} / \mathrm{mL}$ in water). The resulting mixture was allowed to react at room temperature for 1 hour, then the modified Lf was isolated by eluting through a Sephadex ${ }^{\text {TM }}$ PD-10 column with phosphate-buffered saline (PBS) containing $5 \mathrm{mM}$ EDTA. The product obtained was Lf sulfhydryl.

The NB suspension $(1.0 \mathrm{~mL})$ was incubated with $300 \mu \mathrm{L}$ of $\alpha$-Malemidyl- $\omega$-N-hydroxysuccinimidylpoly (ethylene glycol) solution $(0.0047 \mathrm{~g})$. The resulting mixture was maintained at room temperature for 2 hours in the dark. Subsequently, $50 \mu \mathrm{L}$ of glycine solution $(1.0 \mathrm{M})$ was added to quench the reaction. The mixture obtained from the lastmentioned step was further incubated with $2.0 \mathrm{~mL}$ of $\mathrm{Lf}$ sulfhydryl in PBS for 24 hours at room temperature. The Lf-conjugated PAEEP-PLLA NBs (Lf-PAEEP-PLLA NBs) were purified by centrifugation. 


\section{Characterization of Lf-PAEEP-PLLA NBs}

The hydrodynamic size and polydispersity index (PDI) of the Lf-PAEEP-PLLA NBs were measured by photon correlation spectroscopy (Zetasizer Nano ZS90; Malvern Instruments Ltd, Malvern, UK) at $25^{\circ} \mathrm{C}$ using a He-Ne laser of $633 \mathrm{~nm}$. The zeta potential was measured in folded capillary cells using the Zetasizer. The conductivity of the NB solution was adjusted to $50 \mu \mathrm{S} / \mathrm{cm}$ by $0.1 \mathrm{mmol} / \mathrm{L}$ sodium chloride solution for zeta potential measurement. The zeta potential values were calculated using the Helmholtz-Smoluchowski equation.

The concentration of Lf-PAEEP-PLLA NBs was determined with a hemocytometer, using a calculation approach similar to the cell-counting method. In order to obtain direct visualization, the NBs were examined on an inverted fluorescence microscope (Olympus IX71; Olympus Corporation, Tokyo, Japan) with a $400 \times$ magnification in bright and fluorescent visual fields. The formation of conjugated NBs was confirmed by polyacrylamide gel electrophoresis and Fourier transform infrared (FTIR) spectroscopy (Bruker Vertex 70; Bruker Corporation, Billerica, MA, USA).

The morphology of the Lf-PAEEP-PLLA NBs was examined by transmission electron microscopy (TEM) with a $100 \mathrm{kV}$ accelerating voltage. Samples were dropped on an amorphous carbon-coated copper grid. After drying naturally, the grid was negatively stained with $2 \%$ phosphotungstic acid and was observed with TEM.

\section{Cell culture}

Rat C6 glioma (C6) cells, human umbilical vein endothelial (ECV304) cells, and the human normal liver cell line (HL-7702) were purchased from the Shanghai Institute of Life Science Cell Culture Center (Shanghai, People's Republic of China). These cell lines were cultured in Dulbecco's Modified Eagle's Medium (DMEM) with 10\% fetal calf serum (Gibco ${ }^{\circledR}$; Thermo Fisher Scientific, Waltham, MA, USA), penicillin $(100 \mathrm{IU} / \mathrm{mL})$, and streptomycin $(100 \mathrm{mg} / \mathrm{mL})$, under humidified air containing $5 \% \mathrm{CO}_{2}$ at $37^{\circ} \mathrm{C}$. Ethical approval was not sought for the use of human cell lines.

\section{Cytotoxicity assay}

C6 cells and HL-7702 cells were used to evaluate the cytotoxicity with MTT assay. Cells were seeded in 96-well plates at a density of 8,000 cells/well in DMEM. The NBs were added to the cell medium at concentrations of $0.0 \%, 0.5 \%, 1.0 \%$, $2.5 \%, 5.0 \%, 7.5 \%, 10.0 \%, 12.5 \%, 15.0 \%$, and $20.0 \%(\mathrm{v} / \mathrm{v})$ and incubated for 24 hours and 48 hours. The control was the culture medium only. The absorbance at $492 \mathrm{~nm}$ was recorded on a microplate reader (318C Microplate Reader; People's Republic of China).

\section{Hemolysis assay}

Blood samples were collected from the main abdominal artery of Sprague Dawley rats, and placed in a tube containing heparin sodium $(15 \mathrm{IU} / \mathrm{mL})$. The blood samples were centrifuged at 1,500 rpm for 15 minutes to harvest erythrocytes. Erythrocytes collected were resuspended in normal saline to achieve a concentration of $2 \%(\mathrm{v} / \mathrm{v})$. Lf-PAEEP-PLLA NBs were diluted in normal saline to produce suspensions with different concentrations $(0.5 \%, 1.0 \%, 2.5 \%, 5.0 \%, 7.5 \%$, $10.0 \%, 12.5 \%, 15.0 \%$, and $20.0 \%[\mathrm{v} / \mathrm{v}])$. In addition, $150 \mu \mathrm{L}$ of blood diluents was added to $150 \mu \mathrm{L}$ of normal saline as the negative control, and $150 \mu \mathrm{L}$ of double-distilled water was added as the positive control. After 1 hour's incubation in a water bath at $37^{\circ} \mathrm{C}$, the samples were centrifuged at 3,000 rpm for 25 minutes. The resulting supernatant was analyzed using a spectrophotometer at $540 \mathrm{~nm}$. The percentage of hemolysis was calculated with respect to the $100 \%$ hemolysis control.

\section{Effect of Lf on cellular uptake}

Both C6 cells (low-density lipoprotein receptor-related protein 1 (LRP1) positive) and ECV304 cells (LRP1 negative) were used to investigate the cellular uptake of Lf-PAEEPPLLA NBs and non-targeted PAEEP-PLLA NBs. Cells were seeded in 12-well plates at a density of 150,000 cells/well in DMEM, and incubated for 24 hours. Then Lf-PAEEPPLLA NBs or PAEEP-PLLA NBs were added in cell culture medium at concentrations of $5,10,15,20 \mu \mathrm{g} / \mathrm{mL}$. After 2 hours' incubation, the medium was removed and cells were washed with PBS three times. To remove cell debris, samples were centrifuged at 2,000 rpm for 10 minutes, followed by resuspension in double-distilled water. The supernatant was analyzed by flow cytometry (Beckman Coulter Inc, Brea, CA, USA). The NBs were labelled with fluorescent aminoluciferin for the flow cytometric cell-uptake study.

\section{In vitro acoustic behavior}

Lf-PAEEP-PLLA NBs solution was added to the wells of a custom-made $2 \%(\mathrm{w} / \mathrm{v})$ agarose mode, which was positioned in a degassed water bath. The ultrasound contrast results were obtained from a B-mode clinical ultrasound imaging system (Philips NV, Amsterdam, Netherlands). To collect ultrasonic images, the $10 \mathrm{MHz}$ probe of the clinical ultrasound imaging system (L12-1) was employed and immersed in the liquid. All contrast images was recorded in the B-mode, with low persistence, a frame rate of $37 \mathrm{~Hz}$, and a mechanical index of 0.07. Photoshop software (Adobe Systems, Mountain View, CA, USA) was used to perform grayscale image analysis of the samples. 


\section{In vivo ultrasonic imaging study}

All animal studies were approved by the Animal Experimentation Ethics Committee of Huazhong University of Science and Technology, and carried out in compliance with guidelines approved by the Science and Technology Department of Hubei Province.

$\mathrm{BALB} / \mathrm{c}$ nude mice (male, aged 4 weeks, 18-20 g) were used in this study (Animals Center at Tongji Medical College). C6 cells $\left(2 \times 10^{6}\right.$ cells/mouse in $100 \mu \mathrm{L}$ PBS $)$ were subcutaneously injected into the right lower back of the mice. When the tumor volume reached $350-400 \mathrm{~mm}^{3}, 100 \mu \mathrm{L}$ of NBs were injected intra-tumorally. A probe $(10 \mathrm{MHz})$ was placed at the tumor region to obtain images at the time points of 0 seconds, 30 seconds, 10 minutes, and 120 minutes. SonoVue ${ }^{\circledR}$ microbubbles (Bracco Imaging SpA, Milan, Italy), a commercial ultrasonic contrast agent, were used as control.

\section{Statistical analysis}

All data are reported as mean \pm standard deviation. The statistical analysis of the differences among various treatments was performed using unpaired Student's $t$-test. A 0.05 level of probability was used as the level of significance. Analysis of variance was also employed when necessary.

\section{Results and discussion}

\section{Synthesis of PAEEP-PLLA copolymer}

Polyphosphoesters have attracted a great deal of interest in biomedical fields, due to their biocompatibility, biodegradability, functional possibility, and flexibility. ${ }^{27-29}$ As previously reported, polyphosphoesters featuring a linear molecular structure can be synthesized through the ringopening polymerization reaction of EEP in tetrahydrofuran, utilizing $\mathrm{ROH}$ or $\mathrm{RNH}_{2}$ as the co-initiator, and $\mathrm{Sn}(\mathrm{Oct})_{2}$ as the catalyst. ${ }^{30}$ In this work, the PAEEP-PLLA copolymer was synthesized as illustrated in Figure 2. Specifically, EABoc reacted with ethanolamine, and the resulting product was protected with Boc, while the active center of $\mathrm{ROH}$ was retained as the co-initiator. At this stage, the obtained PEEABoc reacted with EABoc and COP. The amino-terminated poly(L-lactide) $(\mathrm{Mn}=18,000)$ was synthesized by the ringopening polymerization reaction of L-lactide using EABoc as the initiator and $\mathrm{Sn}(\mathrm{Oct})_{2}$ as the catalyst. PAEEP-PLLA was synthesized by the ring-opening polymerization reaction of PEEABoc, using amino-terminated poly(L-lactide) as the initiator and $\mathrm{Sn}(\mathrm{Oct})_{2}$ as the catalyst. The structure of products was confirmed by ${ }^{1} \mathrm{H}$ NMR spectroscopy (Figure 1). The polymerization degree of PAEEP was determined using the integrated peak areas at $3.7 \mathrm{ppm}(4 \mathrm{H})$ and $5.2 \mathrm{ppm}(1 \mathrm{H})$, which correspond to the protons of the PLLA block. The PAEEP-PLLA copolymer was composed of a PAEEP segment with a polymerization degree of 30 , and a PLLA segment with a polymerization degree of 130 . Differential scanning calorimetry was employed to investigate the thermal behavior of the crystalline PAEEP-PLLA copolymer. As shown in Figure 3, the differential scanning calorimetry diagrams showed the melting temperature range

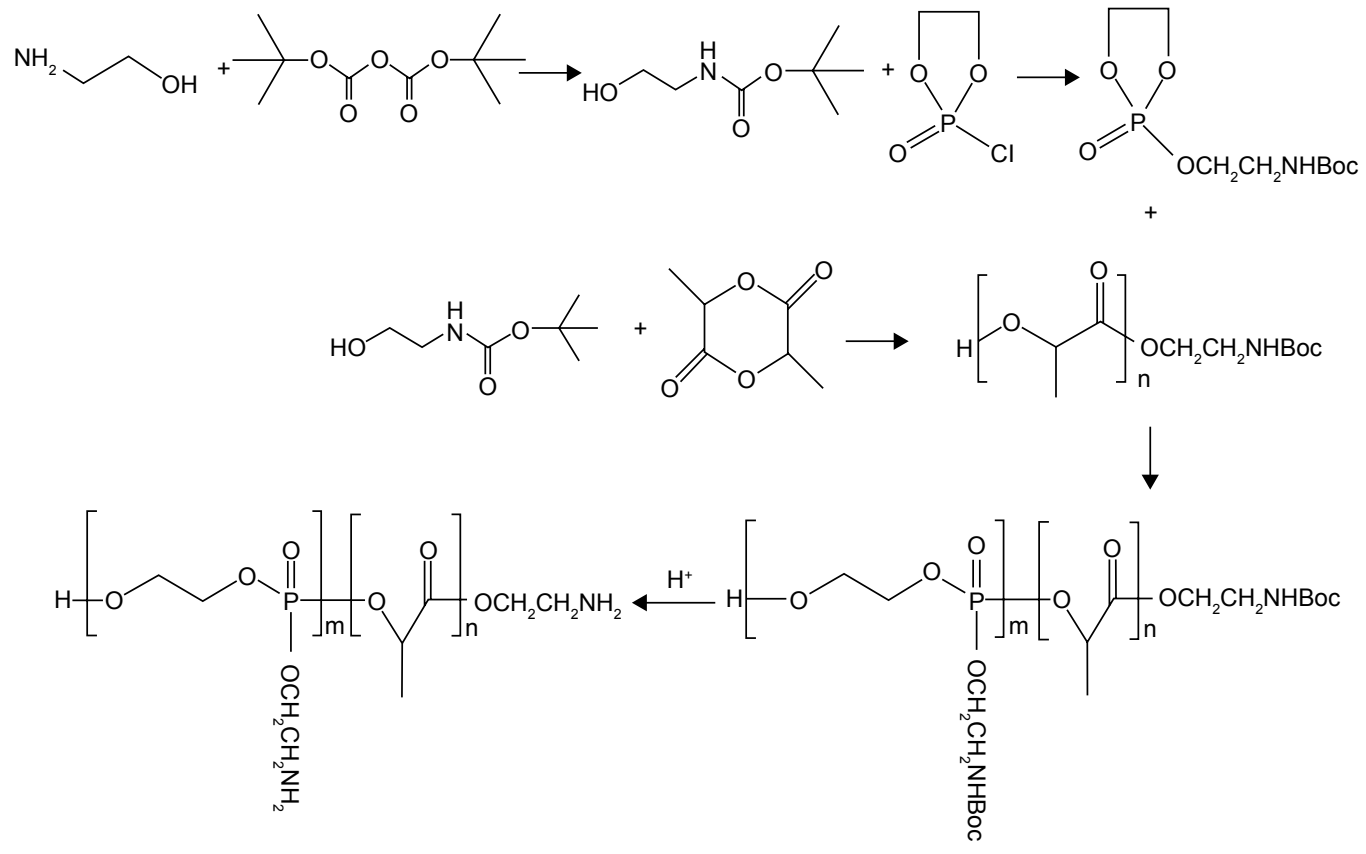

Figure 2 Synthesis procedure of PAEEP-PLLA copolymer.

Abbreviation: PAEEP-PLA, poly(aminoethyl ethylene phosphate)/poly(L-lactide). 


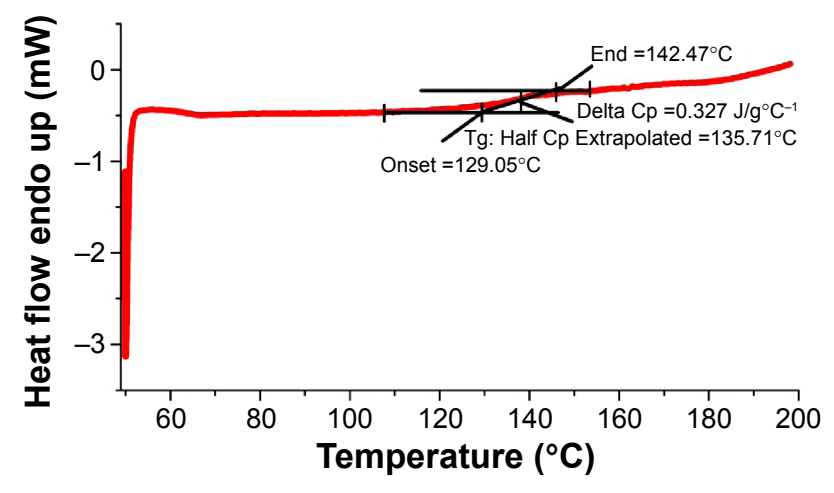

Figure 3 Differential scanning calorimetry (DSC) curve of poly(aminoethyl ethylene phosphate)/poly(L-lactide) copolymer.

Abbreviations: $C_{p}$, heat capacity; $\mathrm{Tg}$, glass-transition temperature.

of PAEEP-PLLA was from $129.05^{\circ} \mathrm{C}$ to $142.47^{\circ} \mathrm{C}$ and the glass-transition temperature $(\mathrm{Tg})$ was $135.71^{\circ} \mathrm{C}$.

Theoretically, the PLLA segment is hydrophobic and the PAEEP segment is highly hydrophilic. The obtained PAEEPPLLA block copolymer was amphipathic with the combined appealing features of PLLA and PAEEP. The mechanical properties, degradation time, and hydrophilic/lipophilic feature of the copolymer can be regulated by selecting a suitable molecular weight, PAEEP/PLLA ratio, and side chain. Therefore, NBs made from PAEEP-PLLA copolymer, as an innovative ultrasonic imaging contrast agent, may have appropriate mechanical properties, good stability, appropriate hydrophilic/lipophilic properties, and moderate degradation time. Hydrophilic polyphosphate chains can effectively prevent the NBs from being cleared by the reticuloendothelial system in the blood. Moreover, the AEEP segment contains a large number of amino groups, which can be readily modified with tumor-targeting molecules.

\section{Preparation of PAEEP-PLLA NBs}

PAEEP-PLLA NBs were prepared using a $\mathrm{O}_{1} / \mathrm{O}_{2} / \mathrm{W}$ doubleemulsion and solvent-evaporation method. PFP, a liquid with a boiling point of $29.5^{\circ} \mathrm{C}$, was employed as the inner core of the NBs. PAEEP-PLLA was used as the shell material of the NBs. The liquid PFP core enhanced the storage stability and ensured the ultrasound-triggered phase-transition capability of the NBs, and can be converted to gaseous PFP at physiological temperature. The PAEEP-PLLA on the surface of the NBs can be conveniently coupled with tumor-targeting molecules.

\section{Conjugation of Lf to PAEEP-PLLA NBs}

Lf was conjugated to PAEEP-PLLA NBs for tumor targeting. The conjugation of Lf through a polyethylene glycol spacer is illustrated in Figure 4. Polyacrylamide gel electrophoresis was used to confirm the conjugation of Lf on the NBs. With the continuous buffer system, the separation by electrophoresis mainly depends on charge and volume effect. Because the isoelectric point of $\mathrm{Lf}$ is about 8.65 , free Lf migrated easily onto the gel at $\mathrm{pH}$ 7.4. On the other hand, the Lf-PAEEPPLLA NBs were negatively charged, as determined by determination of zeta potential, and had large volume. As shown in Figure 5, no migration of Lf was detected after it was conjugated to the NBs, indicating the coupling reaction had been successful.

In the FTIR spectra of Lf-conjugated NBs, two carbonyl absorption peaks at $1,600 \mathrm{~cm}^{-1}$ and $450 \mathrm{~cm}^{-1}$ were observed (Figure 6). However, these peaks were not present in the FTIR spectra of plain NBs. Both electrophoresis and FTIR analysis demonstrated the successful conjugation of Lf to NBs. The concentration of the conjugated
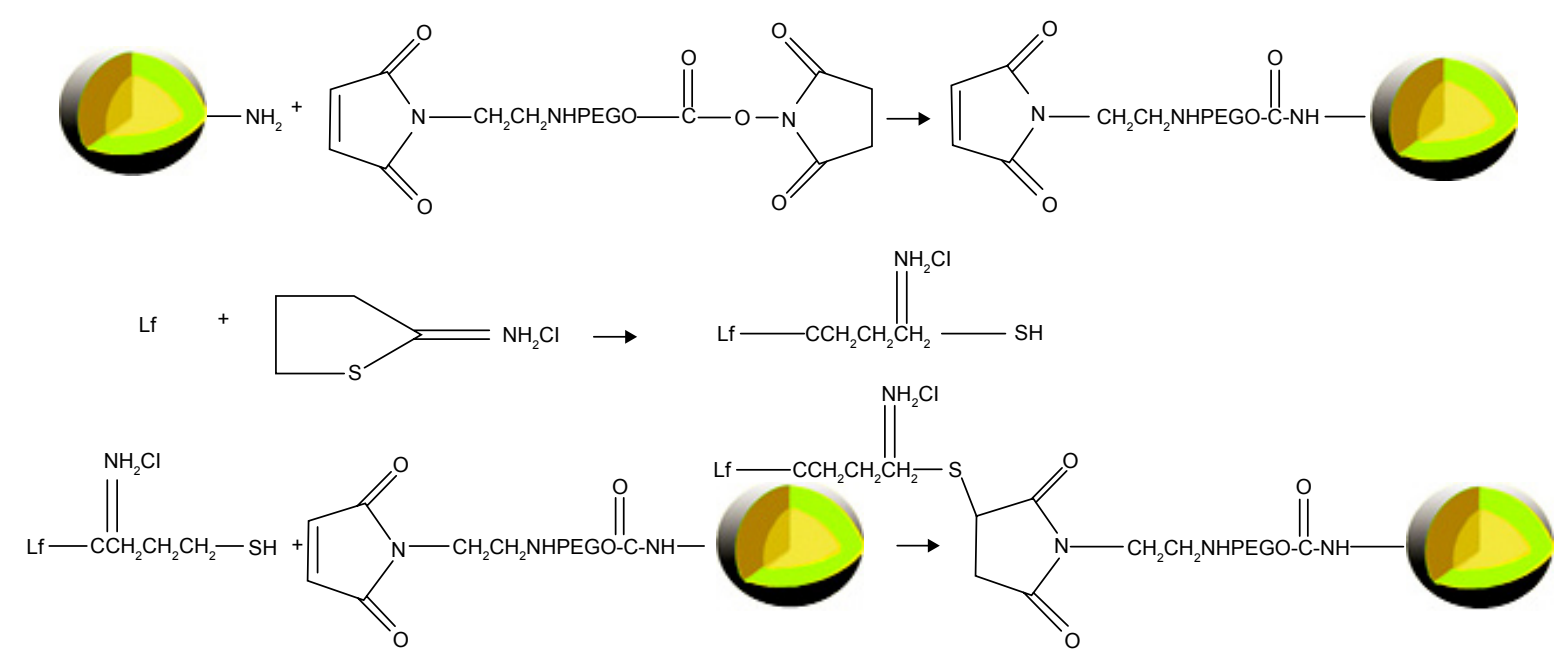

Figure 4 Conjugation of lactoferrin onto the nanobubbles through polyethylene glycol spacers. 


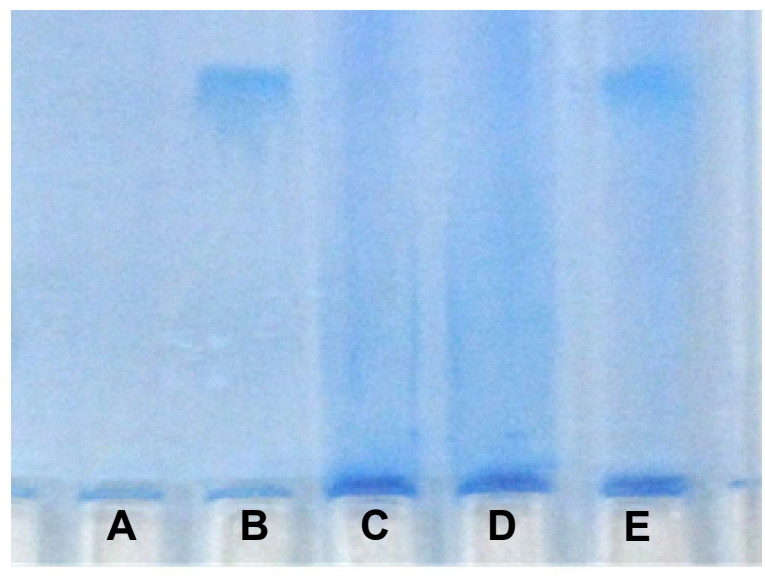

Figure 5 Polyacrylamide gel electrophoresis analysis. Notes: (A) Poly(aminoethyl ethylene phosphate)/poly(L-lactide) (PAEEP-PLLA) nanobubbles (NBs), (B) free lactoferrin (Lf), (C, D) Lf-conjugated PAEEP-PLLA NBs, and (E) a mixture of free Lf and PAEEP-PLLA NBs.

Lf was $0.297 \mathrm{mg} / \mathrm{mL}$, as determined by the bicinchoninic acid method.

\section{Characterization of Lf-PAEEP-PLLA NBs}

The appearance, size/size distribution, and TEM images of Lf-PAEEP-PLLA NBs are shown in Figure 7. The size and size distribution of Lf-PAEEP-PLLA NBs were measured by photon-correlation spectroscopy. An average size of $328.4 \pm 5.1 \mathrm{~nm}$ was found, with a PDI of $0.167 \pm 0.020$, suggesting the NBs were relatively small and quite uniform. The zeta potential of the Lf-PAEEP-PLLA NBs was $-12.6 \pm 0.3 \mathrm{mV}$, which indicates that the NBs were negatively charged when the Lf was conjugated. The number concentration of the LfPAEEP-PLLA NB solution was $1.5 \times 10^{8}$ bubbles $/ \mathrm{mL}$, which

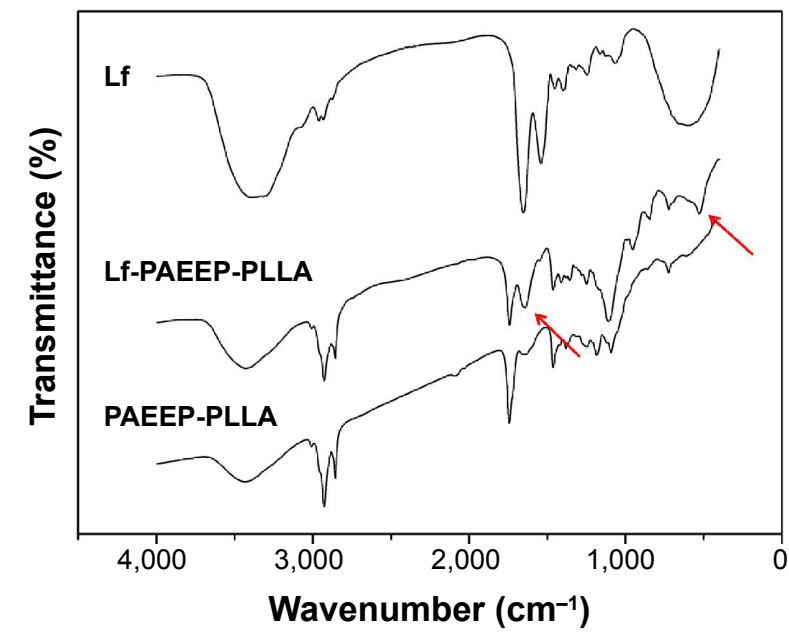

Figure 6 Fourier transform infrared spectra of lactoferrin-conjugated poly(aminoethyl ethylene phosphate)/poly(L-lactide) (Lf-PAEEP-PLLA) and poly(aminoethyl ethylene phosphate)/poly(L-lactide) (PAEEP-PLLA) copolymer.

Note: The red arrows demonstrate the successful conjugation of $L f$ to NBs. Abbreviations: Lf, lactoferrin; NBs, nanobubbles. was determined using a hemocytometer and cell-counting method. TEM images revealed detailed morphological information about the the NBs. Lf-PAEEP-PLLA NBs existed as near-spherical particles and were quite monodisperse. There was a clear interface between the shell and the liquid core inside the NBs.

To evaluate the stability of the NBs, Lf-PAEEP-PLLA $\mathrm{NB}$ aqueous dispersion was stored at $4^{\circ} \mathrm{C}$ for 3 months. Little change was observed in particle size, PDI, and zeta potential during the storage period $(0.0,0.5,1.0$, and 3 months $)$, suggesting the Lf-PAEEP-PLLA NBs had good storage stability (data not shown).

\section{Biocompatibility evaluation of Lf-PAEEP- PLLA NBs}

The biocompatibility of the Lf-PAEEP-PLLA NBs was evaluated by cytotoxicity assay and hemolysis assay. The cytotoxicity of Lf-PAEEP-PLLA NBs was tested using MTT assay for C6 cells and HL7702 cells. The results showed that the NBs did not induce cytotoxicity in C6 cells and HL7702 cells within the concentration range of $0.5 \% \sim 20.0 \%(\mathrm{v} / \mathrm{v})$. Less than $5 \%$ of hemolysis was observed at all evaluated concentrations of the NBs compared to double-distilled water (the positive control) with $100 \%$ of hemolysis under the experimental conditions. Thus, the cytotoxicity and hemolysis studies strongly suggest that the NBs had good biocompatibility for biomedical applications.

\section{Effect of Lf on cellular uptake}

C6 cells are rat glioma cells, which highly express LRP1. ECV304 cells are normal human umbilical vein endothelial cells with no LRP1 expression. Although LRP1 is expressed in some normal tissues, the level of LRP1 in tumor tissues is much higher. ${ }^{31}$ Previous studies have shown that $\mathrm{Lf}$ is a LRP1 ligand, which is a promising targeting ligand for cancer cells. ${ }^{26,32}$ As shown in Figure 8, for C6 cells, the uptake of Lf-PAEEP-PLLA NBs showed a significant increase in comparison with PAEEP-PLLA NBs. However, no obvious change in cellular uptake was observed in the ECV304 cells. The results clearly indicate that the Lf-PAEEP-PLLA NBs exhibited an adequate active tumor-cell targeting ability due to the introduction of the targeting ligand Lf.

\section{Ultrasound-triggered phase transition}

At room temperature, PFP maintained liquid state, and the size of the Lf-PAEEP-PLLA NBs was $328 \mathrm{~nm}$. At physiological temperature $\left(37^{\circ} \mathrm{C}\right)$, although the temperature is above the boiling point of $\mathrm{PFP}\left(29.5^{\circ} \mathrm{C}\right)$, the size of the NBs was only 
A

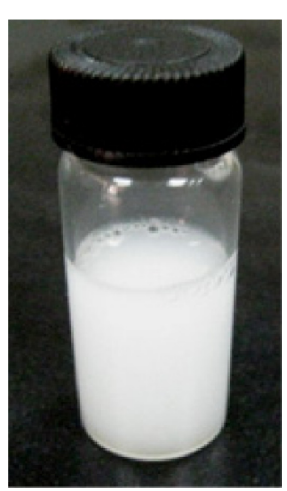

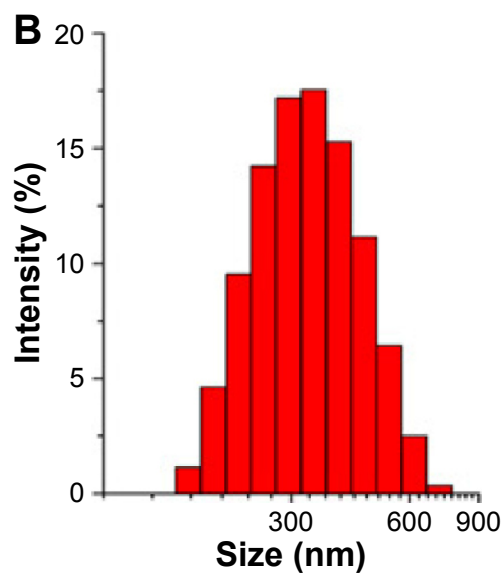

C

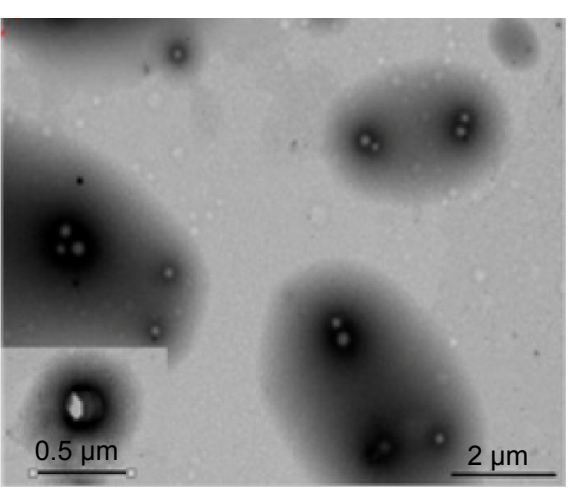

Figure 7 Characterization of lactoferrin-conjugated poly(aminoethyl ethylene phosphate)/poly(L-lactide) nanobubbles: (A) appearance, (B) size distribution, and (C) transmission electron microscopy images.

changed to about $340 \mathrm{~nm}$; so no significant phase transition of PFP occurred. When the temperature reached $50^{\circ} \mathrm{C}$, the size of the NBs increased to about $690 \mathrm{~nm}$, suggesting that phase transition had occurred.

PFP is stabilized by elastic copolymer shells, and its boiling temperature is substantially increased by Laplace pressure. Laplace pressure is generally produced by the pressure difference between the inside and outside of a bubble, due to the surface tension at the interface between the bulk liquid and the bubble liquid. ${ }^{33-35}$

Laplace pressure is given as: $\Delta P=P_{\text {inside }}-P_{\text {outside }}=2 \sigma / r$ in which $P_{\text {inside }}$ is the pressure inside the bubble, $P_{\text {outside }}$ is the pressure outside the bubble, $\sigma$ is the surface tension, and $r$ is the bubble radius. Excessive pressure inside the bubble would result in an increase in the boiling temperature of

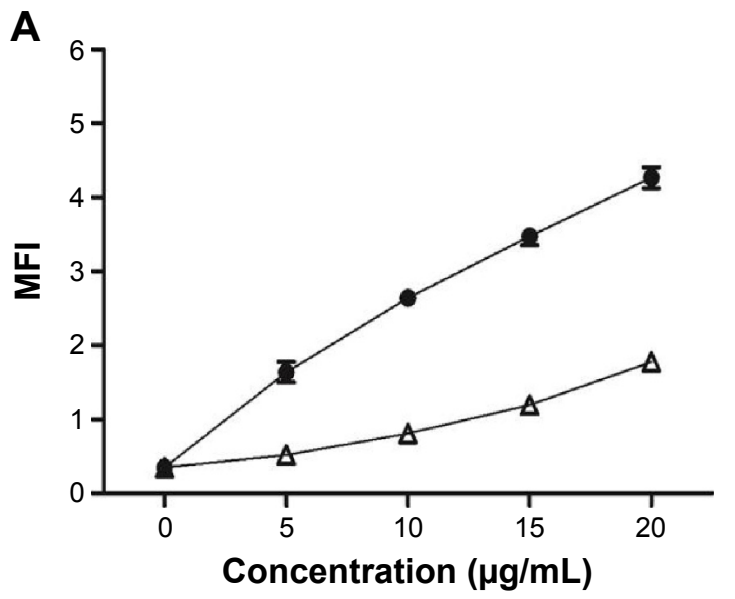

PFP. According to the equation, Laplace pressure is reversely proportional to the radius of the bubble. Therefore, smaller bubbles should have a higher $P_{\text {inside }}$, leading to a higher boiling temperature of PFP.

To evaluate the ultrasonic-triggered phase transition in the NBs, in vitro ultrasonic imaging experiments were performed. During the ultrasonic imaging, the NBs in the agarose model were placed in a water bath, and the temperature was increased from $20^{\circ} \mathrm{C}$ to $38^{\circ} \mathrm{C}$ gradually. As shown in Figure 9, the ultrasonic signals increased with the rise of temperature, and the signals strength reached its maximum at $29^{\circ} \mathrm{C}$. But the signal strength started to decrease when the temperature was gradually increased to $38^{\circ} \mathrm{C}$. Theoretically, the phase transition of PFP is related to two factors, heating and sonication. ${ }^{32}$ In the experiment, the phase transition

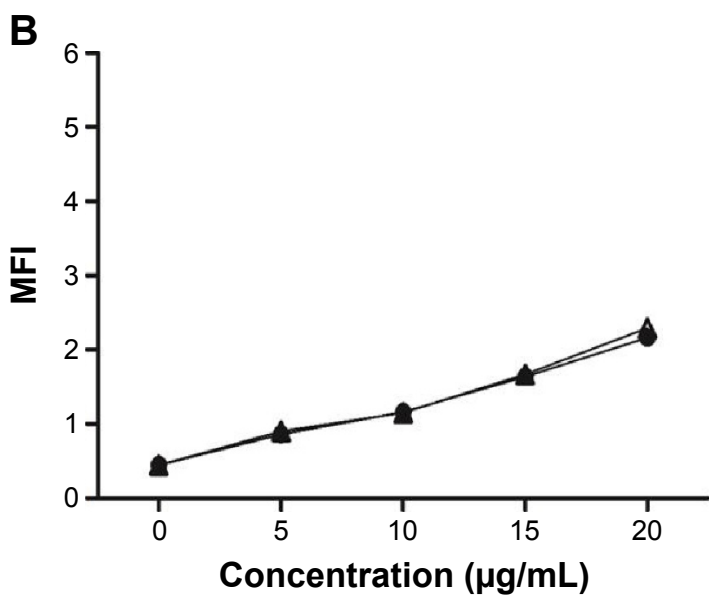

Lf-PAEEP-PLA nanobubbles

Figure 8 Effect of lactoferrin on the cellular uptake: (A) uptake curves of rat C6 glioma cells, (B) uptake curves of human umbilical vein endothelial cells. Note: Data are reported as mean \pm standard deviation $(n=3)$.

Abbreviations: Lf-PAEEP-PLA, lactoferrin-conjugated poly(aminoethyl ethylene phosphate)/poly(L-lactide); PAEEP-PLA, poly(aminoethyl ethylene phosphate)/poly(L-lactide); MFI, mean fluorescence intensity. 

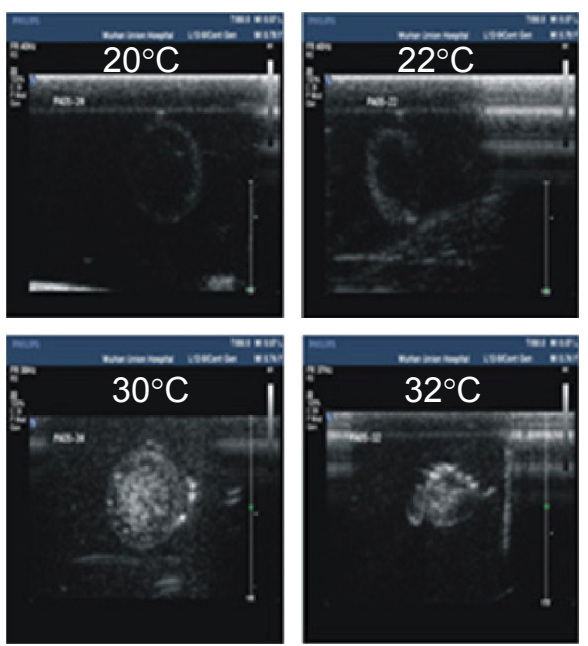
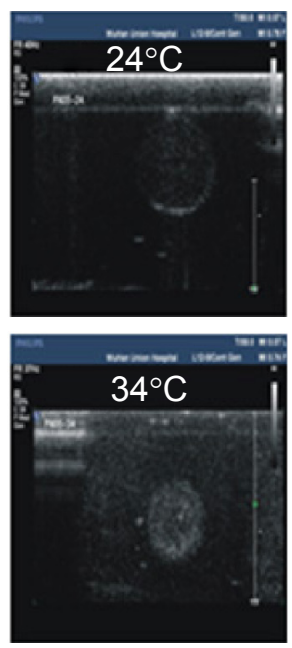
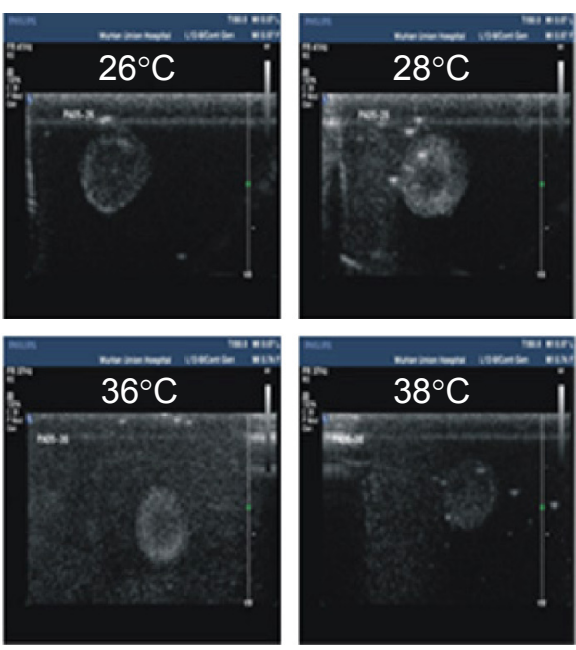

Figure 9 In vitro ultrasonic images of lactoferrin-conjugated poly(aminoethyl ethylene phosphate)/poly(L-lactide) nanobubbles in agarose mold. Note: The temperature was increased from $20^{\circ} \mathrm{C}$ to $38^{\circ} \mathrm{C}$ in $2^{\circ} \mathrm{C}$ intervals.

started at $20^{\circ} \mathrm{C}$ under ultrasonic conditions, indicating that sonication reduced the PFP phase-transition temperature. Sonication appeared to be the most effective factor for PFP phase transition in the NBs.

\section{In vitro ultrasonic imaging}

The PAEEP-PLLA copolymer used as the shell material for the NBs had good mechanical properties, which stretched under ultrasound irradiation. The NBs were turned into larger NBs or microbubbles when the PFP core in the copolymer shell transformed from liquid to gas. It appeared that the NBs in the agarose model oscillated in response to the ultrasonic wave. There was no signal observed when saline was placed in the agarose model. As shown in Figure 10A, the acoustic behavior of the NBs was presented as bright spots, which reflected the echogenic movement signals of the NBs. Naturally, this observation confirms that the NBs possessed acoustic activity.
Ultrasound-targeted microbubble destruction is attractive as a safe, effective, non-invasive, and time- and region-controlled drug-release technology. ${ }^{36,37}$ However, microbubbles prepared from different materials behave differently. For instance, polymer-based shell materials, such as polylactic acid and poly(lactic-co-glycolic acid), have a high destruction threshold under ultrasonic irradiation. Consequently, it is extremely difficult to break up the shell and release its encapsulated cargo. Meanwhile, lipid-based shell materials generally possess a low destruction threshold under ultrasonic irradiation, ${ }^{20,38}$ thus they can be readily destroyed. The shell made from PAEEP-PLLA copolymer developed in the work reported here was effectively destroyed upon ultrasonication. As shown in Figure 10B and C, the signal intensity dramatically decreased compared with that originating from the NBs without flash treatment. Therefore, in addition to a contrast agent for ultrasound, Lf-PAEEP-PLLA NBs may serve as a controlled drug-release system.
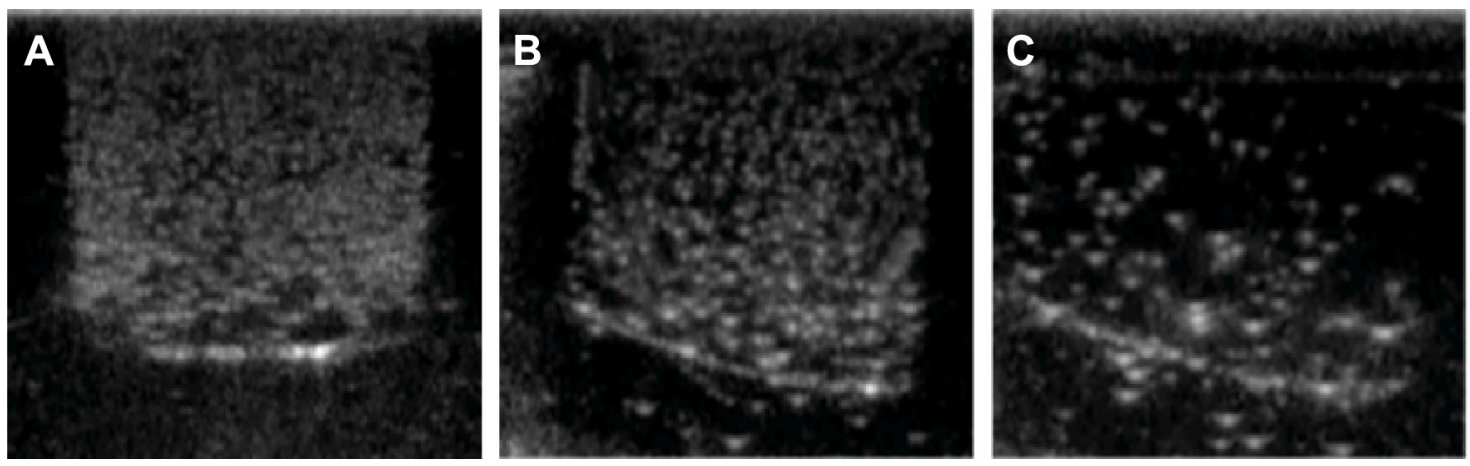

Figure 10 Representative in vitro ultrasonic images.

Notes: (A) The nanobubbles under high-frequency diagnostic ultrasound in agarose mold. (B) Pre-destroyed and (C) post-destroyed of the nanobubbles upon high frequency ultrasound exposure. 

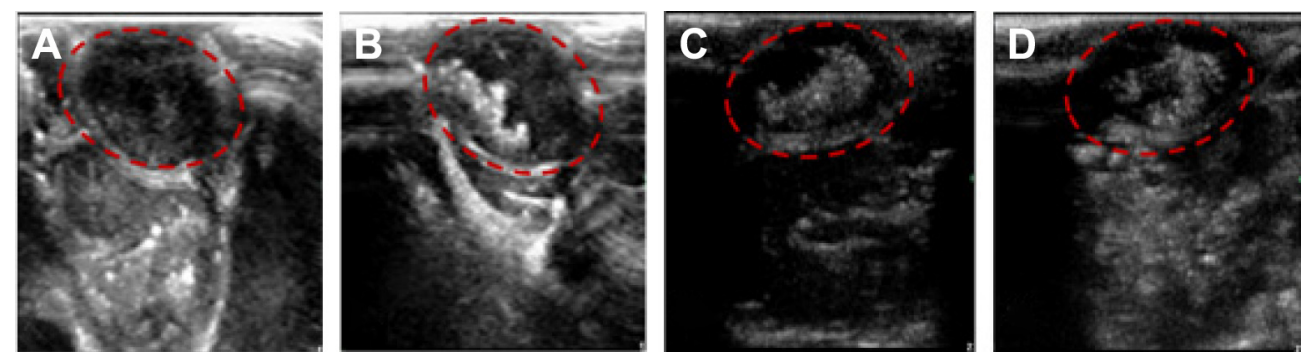

Figure I I Ultrasound images of subcutaneous tumors (red circles) in BALB/c nude mice.

Notes: (A) 0 second, (B) 30 seconds, (C) 10 minutes, and (D) 120 minutes after injection of lactoferrin-conjugated poly(aminoethyl ethylene phosphate)/poly(L-lactide) nanobubbles.

\section{In vivo ultrasonic imaging}

Ultrasonic imaging of subcutaneous tumors in BALB/c nude mice after intra-tumoral injection of $100 \mu \mathrm{L}$ Lf-PAEEP-PLLA NBs was performed using a $10 \mathrm{MHz}$ transducer. Images were recorded at 0 second, 30 seconds, 10 minutes, and 120 minutes after injection (Figure 11). A dark hypoechoic area was found in the tumors before the NBs injection (Figure 11A). Thirty seconds after the injection, some hyperechoic bright spots were found to have been generated in the tumor (Figure 11B). Subsequently, more and more bright spots appeared and a large number of bright spots was observed in the tumor 10 minutes after the injection (Figure 11C). The number of bright spots was not found to have decreased significantly in the tumor at 120 minutes after injection (Figure 11D). The prepared NBs were formed by PFP and stabilized by an outer wall composed of the biodegradable block copolymer. As a result, the PFP stabilized by the outer layer could not diffuse away from the NBs, so the NBs would have longlasting ultrasonic contrast ability. These results suggest that such NBs can be used as a stable and long-lasting contrast agent in clinical ultrasonography.

The performance of the Lf-PAEEP-PLLA NBs was also compared with that of SonoVue, a commercial ultrasonic contrast agent. As shown in Figure 12, the

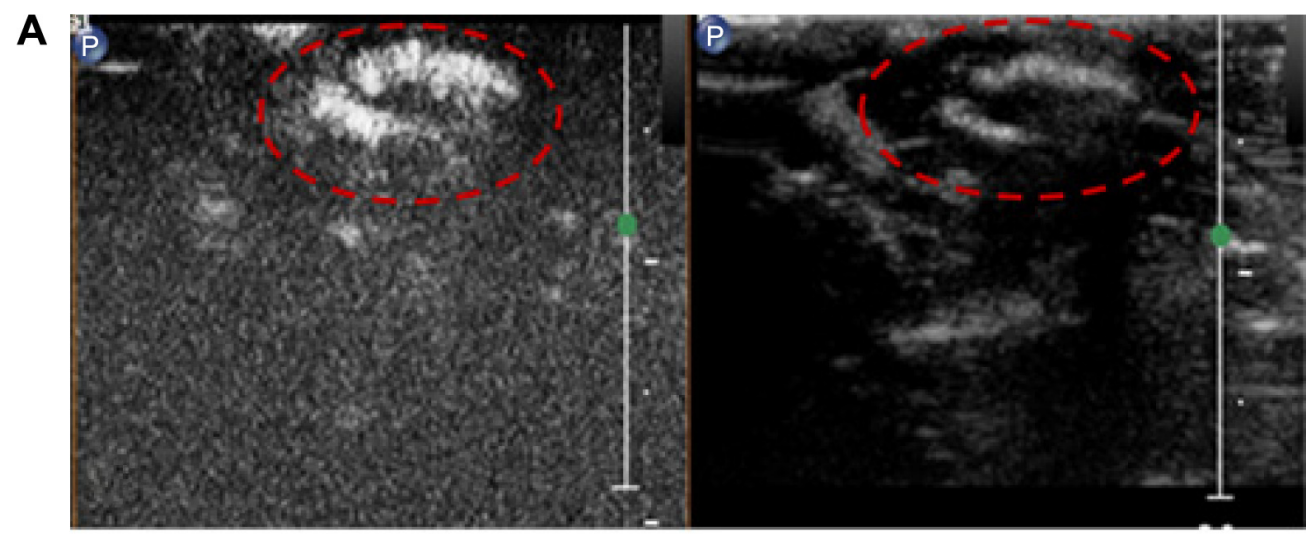

B

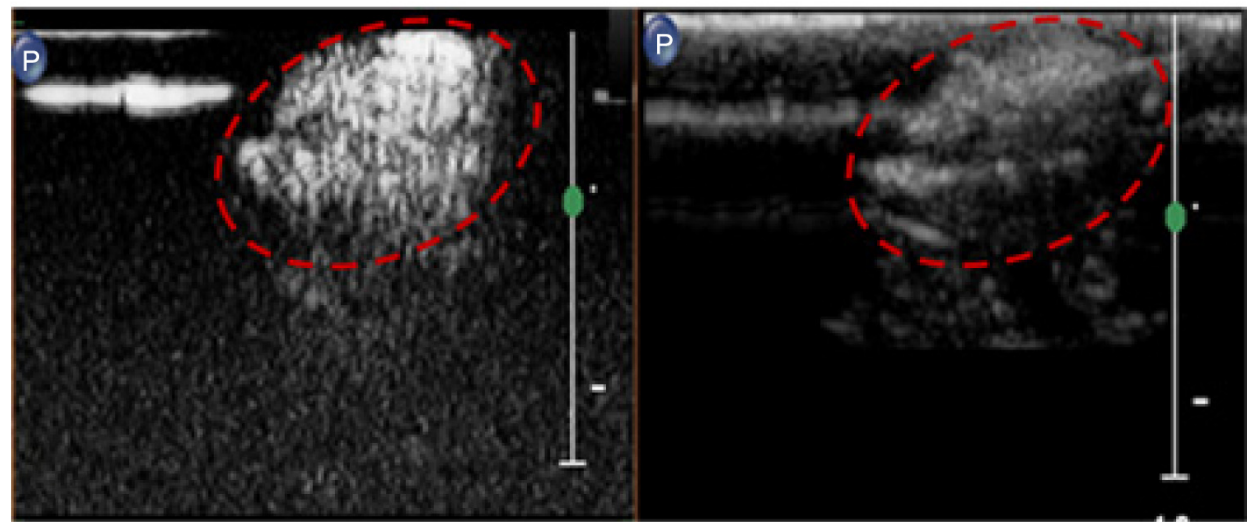

Figure 12 Ultrasound images of subcutaneous tumors (red circles) in BALB/c nude mice after injection of (A) SonoVue ${ }^{\circledR}$ and (B) lactoferrin-conjugated poly(aminoethyl ethylene phosphate)/poly(L-lactide) nanobubbles. 
Lf-PAEEP-PLLA NBs produced a remarkable and complete, powerful Doppler enhancement throughout the tumors, while SonoVue only generated signals in a small part of the tumor. SonoVue is a kind of microbubble, with a larger diameter $(2-8 \mu \mathrm{m})$ compared to our Lf-PAEEPPLLA NBs, so it has been limited to use in diseases of the cardiovascular system. When the SonoVue microbubbles were injected into the tumor, they could not distribute throughout the tumor due to their larger diameter, so only induced contrast enhancement in a small portion of the tumor. However, as the Lf-PAEEP-PLLA NBs were of nanoscale size, they were able to distribute inside the whole tumor, and significant contrast enhancement was observed throughout the tumor. These results successfully demonstrate the great potential of Lf-PAEEP-PLLA NBs as a tumor-targeting imaging reagent.

\section{Conclusion}

In this study, amphiphilic PAEEP-PLLA copolymer was successfully synthesized by ring-opening polymerization reaction. A novel ultrasound contrast agent based on PFP-filled PAEEP-PLLA NBs were prepared using $\mathrm{O}_{1} / \mathrm{O}_{2} / \mathrm{W}$ double-emulsion and solvent-evaporation method. Lf, an effective targeting ligand for cancer cells, was conjugated to the PAEEP-PLLA NBs. The experimental results show that the Lf-PAEEP-PLLA NBs were highly biocompatible and exhibited remarkable tumor-targeting capability. The in vitro and in vivo ultrasound imaging indicate that the Lf-PAEEP-PLLA NBs possessed strong, long-lasting, tumor-targeting, and contrast-enhanced ultrasonic ability. Furthermore, the Lf-PAEEP-PLLA NBs were effectively destroyed upon ultrasonication, indicating they may serve as a controlled drug-release system. In short, the novel Lf-PAEEP-PLLA NBs hold great potential for broad biomedical applications, from ultrasound imaging to the targeted delivery and controlled release of drugs to tumors.

\section{Acknowledgments}

This work was financially supported by the National Science Foundation of China (numbers 31170960, 31470968, and 81271582), the National Basic Research Program of China (973 Program, 2012CB932500), and the National High Technology Research and Development Program of China (863 Program, 2012AA022704).

\section{Disclosure}

The authors report no conflicts of interest in this work.

\section{References}

1. Dănilă M, Popescu A, Sirli R, Sporea I, Martie A, Sendroiu M. Contrast enhanced ultrasound (CEUS) in the evaluation of liver metastases. Med Ultrason. 2010;12(3):233-237.

2. Kiessling F, Fokong S, Koczera P, Lederle W, Lammers T. Ultrasound microbubbles for molecular diagnosis, therapy, and theranostics. J Nucl Med. 2012;53(3):345-348.

3. Wilson SR, Burns PN. Microbubble-enhanced US in body imaging: what role? Radiology. 2010;257(1):24-39.

4. Geers B, Lentacker I, Sanders NN, Demeester J, Meairs S, De Smedt SC. Self-assembled liposome-loaded microbubbles: The missing link for safe and efficient ultrasound triggered drug-delivery. J Control Release. 2011;152(2):249-256.

5. Hernot S, Klibanov AL. Microbubbles in ultrasound-triggered drug and gene delivery. Adv Drug Deliv Rev. 2008;60(10):1153-1166.

6. Lentacker I, De Smedt SC, Sanders NN. Drug loaded microbubble design for ultrasound triggered delivery. Soft Matter. 2009;5(11): 2161-2170.

7. Melino S, Zhou M, Tortora M, Paci M, Cavalieri F, Ashokkumar M. Molecular properties of lysozyme-microbubbles: towards the protein and nucleic acid delivery. Amino Acids. 2012;43(2):885-896.

8. Gessner R, Dayton PA. Advances in molecular imaging with ultrasound. Mol Imaging. 2010;9(3):117-127.

9. Yin T, Wang P, Li J, et al. Ultrasound-sensitive siRNA-loaded nanobubbles formed by hetero-assembly of polymeric micelles and liposomes and their therapeutic effect in gliomas. Biomaterials. 2013;34(18): 4532-4543.

10. Suzuki R, Oda Y, Utoguchi N, Maruyama K. Progress in the development of ultrasound-mediated gene delivery systems utilizing nano- and microbubbles. J Control Release. 2011;149(1):36-41.

11. Yang H, Cai W, Xu L, et al. Nanobubble-Affibody: Novel ultrasound contrast agents for targeted molecular ultrasound imaging of tumor. Biomaterials. 2014;37:279-288.

12. Xu JS, Huang J, Qin R, et al. Synthesizing and binding dual-mode poly (lactic-co-glycolic acid) (PLGA) nanobubbles for cancer targeting and imaging. Biomaterials. 2010;31(7):1716-1722.

13. Torchilin V. Tumor delivery of macromolecular drugs based on the EPR effect. Adv Drug Deliv Rev. 2011;63(3):131-135.

14. Rapoport NY, Kennedy AM, Shea JE, Scaife CL, Nam KH. Controlled and targeted tumor chemotherapy by ultrasound-activated nanoemulsions/ microbubbles. J Control Release. 2009;138(3):268-276.

15. Yin T, Wang $P$, Zheng R, et al. Nanobubbles for enhanced ultrasound imaging of tumors. Int J Nanomedicine. 2012;7:895-904.

16. Zhang X, Zheng Y, Wang Z, et al. Methotrexate-loaded PLGA nanobubbles for ultrasound imaging and Synergistic Targeted therapy of residual tumor during HIFU ablation. Biomaterials. 2014;35(19):5148-5161.

17. Hernot S, Unnikrishnan S, Du Z, et al. Nanobody-coupled microbubbles as novel molecular tracer. $J$ Control Release. 2012;158(2):346-353.

18. Zhang X, Uddin MH, Yang H, et al. Effects of surfactants on the formation and the stability of interfacial nanobubbles. Langmuir. 2012; 28(28):10471-10477.

19. Yin T, Wang P, Li J, et al. Tumor-penetrating codelivery of siRNA and paclitaxel with ultrasound-responsive nanobubbles heteroassembled from polymeric micelles and liposomes. Biomaterials. 2014; 35(22):5932-5943.

20. Böhmer MR, Chlon CH, Raju BI, Chin CT, Shevchenko T, Klibanov AL. Focused ultrasound and microbubbles for enhanced extravasation. J Control Release. 2010;148(1):18-24.

21. Cheng X, LI H, Chen YC, et al. Ultrasound-triggered phase transition sensitive magnetic fluorescent nanodroplets as a multimodal imaging contrast agent in rat and mouse model. PLoS One. 2013; 8(12): 85003.

22. Kim SE, Yun YP, Shim KS, Park K, Choi SW, Suh DH. Effect of lactoferrin-impregnated porous poly(lactide-co-glycolide) (PLGA) microspheres on osteogenic differentiation of rabbit adipose-derived stem cells (rADSCs). Colloid Surfaces B: Biointerfaces. 2014;122: $457-464$. 
23. Li Y, He H, Jia X, Lu WL, Lou J, Wei Y. A dual-targeting nanocarrier based on poly(amidoamine) dendrimers conjugated with transferrin and tamoxifen for treating brain gliomas. Biomaterials. 2012; 33(15):3899-3908.

24. Ha NH, Nair VS, Reddy DN, et al. Lactoferrin-endothelin-1 axis contributes to the development and invasiveness of triple-negative breast cancer phenotypes. Cancer Res. 2011;71(23):7259-7269.

25. Xie H, Zhu Y, Jiang W, et al. Lactoferrin-conjugated superparamagnetic iron oxide nanoparticles as a specific MRI contrast agent for detection of brain glioma in vivo. Biomaterials. 2011;32(2):495-502.

26. Jiang L, Zhou Q, Mu K, et al. pH/temperature sensitive magnetic nanogels conjugated with Cy5.5-labled lactoferrin for MR and fluorescence imaging of glioma in rats. Biomaterials. 2013;34(30):7418-7428.

27. Wang YC, Yuan YY, Du JZ, Yang XZ, Wang J. Recent progress in polyphosphoesters: from controlled synthesis to biomedical applications. Macromol Biosci. 2009;9(12):1154-1164.

28. Zhang P, Hu L, Wang Y, Wang J, Feng L, Li Y. Poly( $\varepsilon$-caprolactone)block-poly(ethyl ethylene phosphate) micelles for brain-targeting drug delivery: in vitro and in vivo valuation. Pharm Res. 2010; 27(12):2657-2669.

29. Sun TM, Du JZ, Yan LF, Mao HQ, Wang J. Self-assembled biodegradable micellar nanoparticles of amphiphilic and cationic block copolymer for siRNA delivery. Biomaterials. 2008;29(32):4348-4355.

30. Xiao CS, Wang YC, Du JZ, Chen XS, Wang J. Kinetics and mechanism of 2-ethoxy-2-oxo-1,3,2-dioxaphospholane polymerization initiated by stannous octoate. Macromolecules. 2006;39:6825-6831.
31. Demeule M, Currie JC, Bertrand Y, et al. Involvement of the low-density lipoprotein receptor-related protein in the transcytosis of the brain delivery vector angiopep-2. J Neurochem. 2008;106(4):1534-1544.

32. Huang R, Ke W, Liu Y, Jiang C, Pei Y. The use of lactoferrin as a ligand for targeting the polyamidoamine-based gene delivery system to the brain. Biomaterials. 2008;29(2):238-246.

33. Cavalli R, Bisazza A, Trotta M, et al. New chitosan nanobubbles for ultrasound-mediated gene delivery: preparation and in vitro characterization. Int J Nanomedicine. 2012;7:3309-3318.

34. Rapoport N, Gao Z, Kennedy A. Multifunctional nanoparticles for combining ultrasonic tumor imaging and targeted chemotherapy. J Natl Cancer Inst. 2007;99(14):1095-1106.

35. Rapoport NY, Efros AL, Christensen DA, Kennedy AM, Nam KH. Microbubble Generation in Phase-Shift Nanoemulsions used as Anticancer Drug Carriers. Bubble Sci Eng Technol. 2009;1(1-2):31-39.

36. Zhou S, Li S, Liu Z, et al. Ultrasound-targeted microbubble destruction mediated herpes simplex virus-thymidine kinase gene treats hepatoma in mice. J Exp Clin Canc Res. 2010;29:170.

37. Luo J, Zhou X, Diao L, Wang Z. Experimental research on wildtype p53 plasmid transfected into retinoblastoma cells and tissues using an ultrasound microbubble intensifier. J Int Med Res. 2010; 38(3):1005-1015.

38. Bloch SH, Wan M, Dayton PA, Ferrara KW. Optical observation of lipid- and polymer-shelled ultrasound microbubble contrast agents. Appl Phys Lett. 2004;84(4):631-633.
International Journal of Nanomedicine

\section{Publish your work in this journal}

The International Journal of Nanomedicine is an international, peerreviewed journal focusing on the application of nanotechnology in diagnostics, therapeutics, and drug delivery systems throughout the biomedical field. This journal is indexed on PubMed Central,

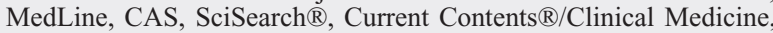

\section{Dovepress}

Journal Citation Reports/Science Edition, EMBase, Scopus and the Elsevier Bibliographic databases. The manuscript management system is completely online and includes a very quick and fair peer-review system, which is all easy to use. Visit http://www.dovepress.com/ testimonials.php to read real quotes from published authors. 